\title{
DAS POSSIBILIDADES DE TRABALHO COM A PSICANÁLISE NO CONTEXTO DE UMA CLÍNICA-ESCOLA
}

\author{
Wânia Suely Santos da Silva
}

Universidade Federal do Maranhão

Luhilda Ribeiro Silveira

Universidade Federal do Maranhão

Gleiciane Mendes Costa

Universidade Federal do Maranhão

Luiza Adelaide Vieira Naue

Universidade Federal do Maranhão

\begin{abstract}
Resumo
Este trabalho decorre da experiência docente e discente em relação à prática da psicanálise em uma clínica-escola de um curso de Psicologia. Situamos, primeiramente, a história da inclusão da psicanálise nos cursos de graduação de psicologia. Em seguida discutimos o ensino teórico e, sobretudo, os desafios que se impõem a uma prática de estágio em clínica psicanalítica frente às questões que circundam e regulamentam o próprio funcionamento da universidade. Nessa via, ressaltamos que a formação do analista não é acadêmica e as diferenças fundamentais entre psicanálise e psicoterapia. Assim, abrimos espaços para que sejam evidenciados os embaraços encontrados na experiência no que toca de perto o estágio em clínica psicanalítica, situado como uma das modalidades de formação em um curso de psicologia, apontando limites e possibilidades de um trabalho que possa se aproximar e abrir caminhos para os alunos que forem capturados pela psicanálise.

Palavras-chave: Psicanálise; Universidade; Clínica-Escola.
\end{abstract}

\section{THE POSSIBILITIES OF WORKING WITH THE PSYCHOANALYSIS IN THE SCHOOL CLINICAL}

\begin{abstract}
This paper comes from professor and students' experience regarding the practice of psychoanalysis in a Clinical School of an undergraduation course of Psychology. First, we presented the history of the introduction of psychoanalysis in undergraduate psychology courses. After, we discussed the theoretical education, and mainly, the challenges to an internship practice in the psychoanalysis clinic facing questions that encompass and regulate the functioning of the University. Thus, we highlight that the psychoanalyst formation is not academic and the fundamental differences between Psychoanalysis and Psychotherapy. Therefore, we discuss the difficulties that are found in the experience related to the internship in psychoanalysis clinic, placed as one of the modalities of formation in a Psychology Course, indicating limits and possibilities of a work that can approximate and expand the minds students who are interested by the psychoanalysis.

Keywords: Psychoanalysis; University; Clinical School.
\end{abstract}




\title{
LAS POSIBILIDADES DE TRABAJO CON EL PSICOANÁLISIS EN EL CONTEXTO DE UNA CLÍNICA-ESCUELA
}

\begin{abstract}
Resumen
Este trabajo surge de la experiencia de docente y estudiantes en relación a la práctica del psicoanálisis en una Clínica Escuela del curso de Psicología. Situamos la historia de la inclusión del psicoanálisis en cursos de grado de psicología. Discutimos la enseñanza teórica y los retos a los que se enfrenta la práctica en una clínica psicoanalítica frente a las cuestiones que circundan y rigen el funcionamiento de la propia universidad. Destacamos que la formación del analista no es académica y las diferencias fundamentales entre el psicoanálisis y la psicoterapia. De esa forma, abrimos espacio para evidenciar los enredos que se encuentran en la experiencia que refieren a la práctica en clínica psicoanalítica, establecida como una de las modalidades de formación en un curso de psicología, señalando límites y posibilidades de un trabajo que pueda aproximar y abrir rutas de acceso para los estudiantes capturados por el psicoanálisis.

Palabras-clave: Psicoanálisis; Universidad; Clínica-Escuela.
\end{abstract}

\section{INTRODUÇÃO}

Apesar dos debates e opiniões divergentes que se irrompem em meio aos questionamentos acerca da universidade ser ou não um espaço para a transmissão da psicanálise, o seu ensino foi se dando ao longo dos tempos, sem que possamos afirmar, com precisão, se houve prejuízos aos seus fundamentos. Podemos com isso, depreender que a academia se tornou um locus para o saber psicanalítico, embora não seja o lugar (ou tenha a pretensão) de formação de analistas, como nos diz Freud (1926/1996) no texto "A questão da análise leiga", em que deixa claro que, a formação ocorre em institutos e que tem, na análise, a via régia do advento de um analista.

Pensando além de uma transmissão teórica, nos propomos a interrogar: 0 que acontece quando a psicanálise é levada para além do estudo teórico, no contexto acadêmico? Formulando de outro modo, o que é possível fazer, em termos da prática clínica, em meio à estrutura universitária?

Observamos que os serviços de psicologia nas universidades, oferecidos geralmente pelas clínicas-escolas, são espaços que propiciam ao aluno uma prática clínica supervisionada, a partir de um percurso acadêmico e, portanto, submetidos às normas que regulamentam a formação de psicólogos. Como afirmam Figueiredo e Vieira (2002), há uma zona fronteiriça entre o saber acadêmico e o analítico. Certamente, há algo de intransponível entre esses saberes. De saída, situamos, nesse contexto, a especificidade do método da psicanálise - a prática clínica.

Partindo dessas observações, nos sentimos convocados a interrogar a prática de estágio em psicanálise, oferecido em uma clínica-escola, considerando a experiência de alunos e sua supervisora. Dedicamo-nos a abrir espaços para refletir sobre os limites e possibilidades de atuação, guiados, em especial, pelos efeitos dessa experiência e pelos fundamentos assentados por Freud e Lacan. 
A fim de mostrar como operamos, iniciaremos com um breve histórico da relação entre a psicanálise e as universidades, destacando pontos que demarcam a sua inserção no ambiente acadêmico, especialmente no Brasil e no Maranhão. Na sequência, faremos uma reflexão sobre a inserção do estágio em clínica psicanalítica na universidade a partir, sobretudo, de uma questão crucial que é a impossibilidade de regulamentação da psicanálise, que não é uma das práticas psicoterapêuticas da psicologia.

De posse desses elementos, ampliamos a questão a fim de alcançar os embaraços com os quais nos deparamos na condução de um trabalho de estágio. Uma empreitada que se dá no intuito de vislumbrar um caminho possível de trabalho, considerando as consequências que dele extraímos, respeitando o fato de que a academia não é um lugar de formação de analistas.

\section{UMA BREVE HISTÓRIA}

A discussão acerca da inserção da psicanálise na universidade não é recente. Freud a inaugura no artigo intitulado "Sobre o ensino da psicanálise nas universidades", publicado em 1919. Nesse texto, constata-se que a motivação era o aperfeiçoamento da formação médica que estava sendo considerada falha, por deixar algumas lacunas no conhecimento médico referente, sobretudo, ao esclarecimento do significado dos fatores mentais nas diferentes funções vitais. O autor indica outro ponto favorável, a preparação para o estudo da psiquiatria. Com isso, para Freud (1919/1996), nesse período, as universidades só teriam a ganhar com essa inclusão e, mesmo não habilitando os estudantes de medicina a serem psicanalistas - sendo necessária uma formação adicional -, poderiam aprender algo sobre a psicanálise.

Assim, historicamente, as universidades vêm se constituindo como um espaço relevante para a difusão do estudo da psicanálise. No Brasil, sua inclusão se deu pelo campo da medicina, tendo como marco histórico a defesa, na Faculdade de Medicina do Rio de Janeiro, da dissertação "Da psicoanálise (a sexualidade das neuroses)" por Genésio Aragão de Sousa Pinto em 1914. Foi por meio da medicina e da saúde pública, a partir do interesse nos estudos de Freud, empreendido por alguns membros da psiquiatria brasileira, que se deu a inserção da psicanálise no meio acadêmico (Oliveira, 2014).

Só mais tarde a Psicanálise passa a estabelecer seus laços com a psicologia. Na verdade, termina se tornando a precursora para a entrada da Psicologia nas universidades brasileiras. Em 1953, Hans Lippman fundou na PUC/RJ o Curso de Psicologia, que viria ser transferido em 1957 para o novo campus da universidade, no bairro da Gávea, no Rio de janeiro, que assim passou a ser dirigido pelo padre Antônio Benkö (Féres-Carneiro, 2013). Este era um entusiasta da Psicanálise e foi quem deu à Psicologia um lugar nessa universidade. 
Em relação ao Maranhão e, mais especificamente, à capital São Luís, local de nosso estudo, é interessante notar que o desenvolvimento da própria psicologia se deu por meio da divulgação da Psicanálise, uma vez que aqui, esta última se estruturou antes da criação dos cursos de Psicologia - tal qual no Rio de Janeiro e em São Paulo. A difusão da psicanálise teve seu início na década de 1980, antes da criação do curso de Psicologia no Maranhão (Araújo, 2005). É assim que o histórico da psicanálise no Maranhão nos conduz à relação com a universidade, em nosso caso específico, a Universidade Federal do Maranhão (UFMA), pois muito dos primeiros professores do curso de psicologia eram psicanalistas. Para efeito de trabalho, decidimos de certa forma trazer essa discussão através da problemática que nos interessa seguir e que reafirmamos a partir de e com Freud: a psicanálise é leiga. Tocados muito de perto por essa questão, trataremos do seu ensino e sua prática supervisionada nos cursos de psicologia da instituição mencionada.

\section{O ENSINO DA PSICANÁLISE VERSUS FORMAÇÃO DE ANALISTA}

O ensino da psicanálise nas universidades não se dá mais, predominantemente, pela via da medicina, como até meados do século $X X$ e, sim, por meio do curso de psicologia. Na realidade, tradicionalmente, a psicanálise é entendida como ramo da psicologia ou da medicina e provavelmente esse fato deve-se a várias tentativas de profissionalizá-la, herança de um questionamento que se dá desde Freud, a saber: o que regula a psicanálise?

A psicanálise é um ofício e não uma profissão que se chega com um diploma. Está incluída na Classificação Brasileira de Ocupações (CBO; Ministério do Trabalho e do Emprego, 2002) que não tem função de regulamentar, mas apenas de reconhecer as ocupações por meio de pesquisa de campo. Os pesquisadores identificam e descrevem as ocupações existentes no mercado de trabalho e, assim, apenas reconhecem a ocupação. A regulamentação pressupõe o estabelecimento de qualificação, critérios e condições para o exercício de atividade profissional e é realizada por lei, cuja apreciação é feita pelo Congresso Nacional.

Em 1926, Freud escreveu o texto "A questão da análise leiga", que teve como objetivo mostrar que o saber analítico não se aprende nos livros, tampouco, na universidade. Para a formação do analista deixa claro, um tripé de formação assentado no estudo teórico, supervisão e análise pessoal. Mesmo nos dias atuais, este texto conserva seu caráter revolucionário, pois trata de um modo de transmissão diferente do acadêmico, em que a formação do analista não pode ser reduzida a um saber meramente técnico. O autor defende nele o exercício da prática analítica por aqueles que tiveram realizado um percurso de análise e não fruto de um conhecimento adquirido através de diplomas. 
O texto, referido acima, nos serve para pensarmos a inclusão da psicanálise nos cursos de graduação de psicologia e acompanha uma preocupação à qual Freud (1919/1996) era bem sensível, levando-o, inclusive, ao seguinte questionamento: como incorporar a psicanálise à estrutura educacional regular? Entendemos, com isso, que o autor não inviabiliza o estudo da psicanálise na universidade, até reconhece sua importância, porém, com os devidos cuidados, pois tem como guia o fato de a universidade não ser o lugar de formação de analistas.

É nessa perspectiva que, nossas indagações se ampliam e tomam forma com o que constitui o cerne da presente discussão: o que tem sido possível fazer a partir da forma como a psicanálise tem se estruturado no curso de psicologia, sobretudo, no estágio em clínica psicanalítica e as implicações disso para discentes/estagiários, docentes/supervisores e para a comunidade que faz uso do serviço da clínica? Essa questão nos segue considerando o que constitui o campo singular da psicanálise, a rigor, a renúncia a um objetivo terapêutico. Um pouco adiante, esclarecemos em que essa afirmação se apoia e o que significa.

A fim de darmos um encaminhamento para as questões que se abriram, passaremos a mostrar como se dá o ensino da psicanálise na Universidade Federal do Maranhão, apontando o que, até então, tem sido possível de ser feito como um trabalho, com o referencial da psicanálise.

\section{A PSICANÁLISE NA UNIVERSIDADE FEDERAL DO MARANHÃO (UFMA): DO QUE SE TRATA?}

No curso de psicologia da UFMA o estudo da psicanálise, atualmente, é possível a partir de 4 disciplinas: Fundamentos da Clínica Freudiana, Fundamentos da Clínica Lacaniana e Terapias e Técnicas Psicoterápicas I e II. Há, ainda, a possibilidade de se realizar o estágio obrigatório em clínica psicanalítica, uma das modalidades de estágio em clínica, oferecidas pelo Núcleo de Psicologia Aplicada (NPA) da UFMA. Este Núcleo visa o atendimento da comunidade acadêmica e da comunidade em geral, tendo como foco prioritário o público de baixa renda.

Os atendimentos realizados no NPA são realizados exclusivamente pelos estagiários sob a supervisão de um docente e, em se tratando de um serviço de atendimento de uma clínica-escola do curso de psicologia, esse é um espaço que tem diretrizes e normas estabelecidas em função de atender à exigência de órgãos que regulamentam as instituições de ensino superior, a exemplo do Ministério da Educação (MEC).

O serviço de atendimento em psicologia nas universidades é uma atividade que historicamente se constituiu como exigência legal, no intuito de consolidar competências no âmbito de uma prática profissional. A Lei 4.119 de 27 de agosto de 1962, que dispõe sobre os cursos de formação em psicologia e regulamenta a 
profissão de psicólogo, já trazia em seu Cap. IV, Art. 16, a seguinte diretriz: "As Faculdades que mantiverem curso de Psicólogo deverão organizar Serviços Clínicos e de aplicação à educação e ao trabalho - orientados e dirigidos pelo Conselho dos Professores do curso-abertos ao público, gratuitos ou remunerados" (Presidência da República do Brasil, 1962).

Além da Lei 4.119 , outros dispositivos legais também incidem sobre a as práticas dos serviços de psicologia oferecidos em clínicas-escola. Tais atividades de atendimento devem seguir padrões de funcionamento estabelecidos no documento intitulado "Padrões de Qualidade para Cursos de Graduação em Psicologia". Estes padrões constituem a referência para os procedimentos de avaliação dos cursos pelo MEC e "têm por objetivo estabelecer e definir padrões, critérios e indicadores de qualidade para a criação e funcionamento do curso de graduação em Psicologia" (Ministério da Educação [MEC], 2000, p. 2).

Para uma avaliação do serviço de psicologia são considerados: a articulação das atividades desenvolvidas no serviço com as demais atividades do curso; se as atividades desenvolvidas contemplam demandas de atendimento psicológico da comunidade; a qualidade do sistema de registro dos serviços prestados, incluindo os prontuários; acesso e seleção dos usuários do serviço; se as atividades desenvolvidas contemplam as necessidades de formação do psicólogo conforme previstas no curso, dentre outros aspectos (MEC, 2000).

Existem ainda as Diretrizes Curriculares Nacionais para os Cursos de Psicologia, instrumento também formulado pelo MEC, que estabelece as normas a serem observadas pelas instituições de ensino superior do país para os cursos de graduação em psicologia, que em seu Art. 25 define que:

O projeto de curso deve prever a instalação de um Serviço de Psicologia com as funções de responder às exigências para a formação do psicólogo, congruente com as competências que o curso objetiva desenvolver no aluno e as demandas de serviço psicológico da comunidade na qual está inserido (MEC, 2011, p. 8).

Ainda que os critérios estabelecidos pelo MEC sejam de uma ordem ampla, em que a pluralidade, o caráter de formação generalista, prevalece. Pensar certos aspectos da inserção da psicanálise atrelada para além do estudo teórico, mas inserida numa prática dentro do contexto universitário, como é o caso do estágio em clínica psicanalítica oferecido num Serviço de Psicologia, é algo que nos instiga e que por vezes nos desafia em termos da realização de um trabalho, uma vez que o foco é a formação do psicólogo no bojo do que seriam suas competências.

Considerando que os Serviços de Psicologia oferecidos pelas clínicas-escola nas universidades se constituem como espaço para a prática do estágio obrigatório, A Lei do Estágio é mais um instrumento regulatório que deve ser considerado nesse cenário. A Lei n. ${ }^{0} 11.788 / 2008$ que regulamenta as atividades 
de estágio realizadas por estudantes em todos os níveis de formação, em seu Art. $1^{\circ}$ define que:

Art. 10 Estágio é ato educativo escolar supervisionado, desenvolvido no ambiente de trabalho, que visa à preparação para o trabalho produtivo de educandos que estejam frequentando o ensino regular em instituições de educação superior, de educação profissional, de ensino médio, da educação especial e dos anos finais do ensino fundamental, na modalidade profissional da educação de jovens e adultos.

$\S 10$ O estágio faz parte do projeto pedagógico do curso, além de integrar o itinerário formativo do educando.

§ 20 O estágio visa ao aprendizado de competências próprias da atividade profissional e à contextualização curricular, objetivando o desenvolvimento do educando para a vida cidadã e para o trabalho (Presidência da República do Brasil, 2008).

No que diz respeito à prática clínica os estágios são realizados em um serviço de clínica-escola, segundo o MEC (2000), a infraestrutura física dos serviços de psicologia diz respeito aos materiais especializados e equipamentos, condições e critérios de acesso ao público e devem contemplar: espaço físico previsto; localização, acesso e condições de comunicação; condições de acesso, espera e atendimento do público; divisão de espaço para os serviços técnicos, administrativos e de supervisão; iluminação e ventilação adequadas; mobiliário compatível às atividades de atendimento; isolamento acústico e outros cuidados técnicos; instalações sanitárias e outras facilidades ao público; sistema de arquivo e prontuários.

Na UFMA, a clínica-escola situa-se dentro da própria instituição, mais precisamente, no Centro de Ciências Humanas. Todos os ambientes são devidamente mobiliados para o atendimento ao usuário. Quanto ao procedimento para a solicitação do serviço, este se dá, primeiramente, por meio de uma inscrição que pode ser realizada presencialmente ou por telefone. Para esse momento são solicitados dados pessoais como nome, endereço, telefone e em alguns casos são sinalizados urgência ou encaminhamento de outras instituições, condições que são consideradas prioridades para o atendimento.

Após a inscrição, o solicitante aguarda ser chamado para realizar uma triagem. Esta consiste em uma entrevista, realizada pelos estagiários, que visa avaliar se o caso em questão é viável para atendimento no NPA. A viabilidade é identificada por meio da renda do usuário, pois como já mencionado, a clínicaescola é restrita ao público de baixa-renda, e também por meio da queixa trazida pelo solicitante. Os usuários que não estiverem de acordo com tais requisitos são comunicados e encaminhados a outros serviços, os demais ficam no aguardo do atendimento.

No início do atendimento é fornecido ao usuário um termo de compromisso em que constam algumas normas e regras do funcionamento do NPA, dentre elas: os atendimentos serão realizados durante um período que se limita ao 
término do estágio, sendo que, caso queira, o paciente pode solicitar continuar os atendimentos com outro estagiário, mas isso só é possível uma vez; para os atendimentos, na clínica-psicanalítica, é necessário o pagamento de uma taxa, o que não é necessário em outras práticas do núcleo.

Em linhas gerais, mostramos o funcionamento do NPA, que abrange o estágio em diversas práticas psicoterapêuticas da psicologia, que como mostramos, são regidas por critérios bem definidos pelo MEC. O NPA é o local em que realizamos nosso trabalho, e, através do qual podemos problematizá-lo, refletindo sobre suas possibilidades, a partir dos fundamentos da psicanálise. Temos a preocupação constante em preservar a singularidade do campo analítico e não o abarcar ao contexto de formação acadêmica, que o colocaria vinculado ao curso de psicologia e às suas normas de regulamentação. $E$, no contexto que nos acompanha, somos convocados a problematizar a inclusão da psicanálise como uma prática psicoterapêutica.

\section{OS IMPASSES DA INCLUSÃO DO ESTÁGIO EM PSICANÁLISE NA UNIVERSIDADE A PARTIR DA SINGULARIDADE DE SEU CAMPO}

Considerando toda a conjuntura da formação acadêmica na universidade e o contexto mostrado, que implica em um conjunto de regulamentações, tomamos agora como fio condutor da nossa discussão, a diferença entre psicanálise e psicoterapia. A escolha de seguir esse fio se justifica no cenário, que não é recente de tentativas de regulamentar o ofício de psicanalista, a fim de impedir a prática abusiva, sustentada por apropriações indevidas dos fundamentos que a sustentam. É nessa direção que seguem movimentos de incluí-la como uma das psicoterapias do curso de psicologia e aí deixar sua prática restrita à formação acadêmica, ou melhor, submetida a ela.

A partir da década de 1970, verificamos em nosso país vários projetos de lei que tinham a finalidade de profissionalizar a psicanálise. Tais projetos foram arquivados devido à força das instituições de psicanálise, que se colocaram contra essas tentativas. Podemos situar como auge desse debate, o surgimento de agências vinculadas a grupos evangélicos, que formavam turmas com o objetivo de fornecer diplomas de psicanalistas e iam atingindo números cada vez maiores em todo o país. Essa situação mobilizou entidades psicanalíticas brasileiras no sentido de constituir fóruns a fim de dar efetividade às ações, e têm no ano 2000, seu início. Alguns conselhos reguladores fizeram parte desse movimento, como o Conselho Federal de Psicologia (CFP), Conselho Federal de Medicina (CFM) e a Associação Brasileira de Psiquiatria (ABP).

A Articulação das Entidades Psicanalíticas Brasileiras, embora não seja uma instituição, é formada por psicanalistas de várias instituições do país. É um movimento pronto para tomar posição quando perceber ações que claramente ferem os princípios conceituais e éticos da psicanálise. O trabalho iniciado no ano 
de 2000 pelas entidades de articulação de psicanálise resultou em uma coletânea de artigos intitulado "O ofício do Psicanalista" e traz a discussão para um debate com um público que vai para além dos analistas. Podemos considerá-lo mais um movimento no sentido de tornar público questões acerca da impossibilidade da regulamentação da psicanálise, demarcando diferenças significativas entre psicanálise e psicoterapia.

Lacan no texto "A direção do tratamento e os princípios do seu poder" (1958/1998) diz que o analista dirige o tratamento, porém, de modo algum, dirige o paciente. Nesse texto, há uma insistência do autor em retirar da situação analítica o caráter dual, próprio das relações simétricas, que regem as práticas psicoterapêuticas. Nestas, a condução do tratamento é organizada de modo que o lugar do terapeuta esteja regido por uma posição de saber prévio que orienta sua ação. Saber esse guiado por uma determinada concepção do mundo, de saúde mental ou de domínio de uma técnica a ser bem executada, com objetivo da eliminação do sintoma e restauração de uma ordem harmoniosa com o mundo. A condução é orientada para a superação do conflito, em que o saber sustenta a noção de bem-estar a ser atingido (Góes, 2009).

Em Freud (1926/1996), identificamos cada vez mais o distanciamento da ilusão de um saber prévio, totalizante e cumulativo em relação à formação do analista. Não há um saber de domínio sobre o inconsciente, tendo em vista, fundamentalmente, que é ele que nos sabe. Podemos, com o autor, chegar a considerar impostura a posição de domínio do inconsciente, garantido por uma formação acadêmica.

Esse fio de distinção é suficiente para que certos temas surjam e nos coloca diante de algumas questões cruciais: como inserir dispositivos analíticos na prática de uma clínica-escola? Como inserir, nesse espaço, o fundamento da escuta analítica (escuta do sujeito desejante) e, portanto, sujeito faltoso?

Nessa perspectiva, podemos elencar alguns pontos que devem ser considerados para uma reflexão acerca dessa prática. Chamamos a atenção para o fato de que elegemos um número restrito de questões para efeito de problematizá-la, nesse contexto. Sabemos que as interrogações não se limitam ao que por ora desenvolvemos, mas se abrem, sobretudo, levando em consideração que, uma clínica-escola, não é uma clínica particular. Desse modo, buscam-se alternativas de intervenção pautadas nos aspectos conceituais da clínica psicanalítica.

Assim, o estágio em clínica psicanalítica visa a formação de psicólogos que possam pensar a constituição de um sujeito efeito do inconsciente. Primeiramente, a linguagem toma lugar central na prática de escuta do supervisionando, ajuda/auxilia o estagiário a ter no centro de sua escuta um sujeito inscrito e constituído pela linguagem. Pensando desse modo, entendemos que um profissional, que leva em conta o inconsciente, assume uma prática que tem na escuta do sofrimento, o seu diferencial. Com efeito, o sintoma tem, 
desde Freud (1916/1996), um lugar de substituto de um conflito psíquico que não encontra outra via de expressão. Desse modo, a queixa do sujeito diz algo da sua maneira de estar no mundo, o que nos conduz a não visarmos, de saída, a eliminação do sintoma, e, sim a leitura, através de uma escuta, do lugar que ocupa, na economia psíquica do sujeito.

A direção da intervenção é a de levar o usuário a refletir sobre aquilo de que se queixa, levando-o a se incluir em sua queixa. É a condução para uma retificação subjetiva, um dos recursos da clínica psicanalítica, enunciados por Freud (1905/1996). Seria, grosso modo, a introdução do sujeito na realidade de seu sofrimento. O que guia a intervenção é a introdução do paciente em uma primeira localização de sua posição, com a questão fundamental que se refere à qual a sua participação na desordem da qual se queixa. Esse é um primeiro giro subjetivo, que dá início a um deslocamento facilitador de ressignificações de sentido. Há, com efeito, a possibilidade de aberturas na cadeia associativa do sujeito, que o conduz para novas questões, ponto que poderíamos considerar de encerramento do caso, encaminhando-o para outro tipo de trabalho, em outro lugar. Abrimos um breve espaço para deixar claro que, uma análise propriamente não é feita apenas de retificações e sim de vários dispositivos e recursos, não contemplados nesse serviço.

Toda intervenção só será possível através da transferência. Conceito este crucial na psicanálise, pois, trata-se da repetição, na atualidade, de modelos de relações infantis, é assim, a inclusão do analista na série psíquica do paciente (Freud, 1912/1996). É ela que permitirá que o sujeito se enlace no trabalho. Apesar de não se tratar, no NPA, de um trabalho propriamente analítico, como insistentemente afirmamos, pois se trata, nesse caso, de um curso universitário, conservamos a transferência como dispositivo clínico-conceitual que utilizamos, pois é o motor do trabalho e, como nos diz Lacan (1964/1998) é a colocação do inconsciente em ato.

Por outro lado, não deixamos de reconhecer as dificuldades implicadas em uma prática analítica na clínica-escola que tem um tempo limitado, pois os alunos ficam por um período de um ano, tempo em que conduzem os tratamentos. O usuário, por sua vez, sabe disso, o que certamente traz implicações para o laço estabelecido.

Por essa via é que nos deparamos com a problemática ética que rege nosso trabalho e nos interrogamos sobre o que deve sustentar a escuta que ali é feita. A ética das práticas psicoterápicas está organizada em torno da busca pelo bem do sujeito, partem da ideia de que é possível saber o que será bom para o outro. A psicanálise não parte desses pressupostos, em uma prática analítica não teremos como guia um saber prévio sobre o que é bom para o outro, pois se assim o fizesse, apenas repetiria o que já está ali posto na sua economia psíquica e o desresponsabilizaria de suas escolhas. 
A ética da psicanálise dirige o sujeito para uma posição desejante, o que implicaria o distanciamento de padrões normativos. De forma sucinta, é o que nos conduziria à nossa falta constitutiva, uma posição subjetiva diante do vazio que, permitiria nos arriscarmos na vida sem tantos constrangimentos diante da imagem. Podemos encontrar indícios dessa afirmação, no texto Variantes de um tratamento padrão, em que Lacan (1955/1994) apoia-se em Freud para afirmar que análise é o que se espera de um analista. Discorre longamente, nessa obra, que é no rigor ético da psicanálise que podemos encontrar sua diferença em relação às práticas psicoterapêuticas. Ética do desejo, que não corresponde a visar o bem, tampouco, o mal do paciente.

Pensando no NPA, como não sermos tentados a fazer o bem do sujeito e nos preocuparmos em produzir manifestações imediatas de melhora do seu sofrimento? Aliás, teremos finalidades terapêuticas? Dissemos, anteriormente, que psicanálise não é psicoterapia, afirmação suficiente para cavar um abismo diante da prática psicanalítica e da psicologia.

O que temos em mãos, no momento para o trabalho, são os elementos que mostramos, estes são interrogados a cada vez que os colocamos em prática. Por outro lado, estamos buscando uma maneira possível de trabalho que, a princípio, nos convoca a pensar que a Psicanálise traz como consequência uma relativização do saber no campo acadêmico. No que toca de perto a formação dos alunos, acreditamos estar abrindo um espaço inicial de contato com essa prática e com Lacan (1955/1994) deixando claro que, fora do rigor da ética da psicanálise, qualquer tratamento, mesmo recheado de conhecimentos psicanalíticos, não passa de psicoterapia.

\section{CONSIDERAÇÕES FINAIS}

A universidade é um espaço de aquisição e prática de conhecimento e, como vimos acabou por abarcar a psicanálise. A questão que trouxemos se situa no âmbito do que é possível ser feito dentro da universidade, em termos de sua prática na clínica-escola. Essa reflexão é imprescindível para a atuação de supervisores e estagiários, uma vez que os primeiros estão em constante processo de formação e os últimos estão começando a trilhar um percurso na psicanálise. Percurso este que requer algo para além do estudo da teoria.

Apesar de a difusão da psicanálise ser amplamente reconhecida nas universidades, tal inserção nunca se apresentou de forma pacífica. No tocante a sua prática, nas clínicas-escolas, implica em limitações que encontramos em diversos aspectos. Estamos diante de um tempo restrito para a execução de um trabalho, assim como de percurso incipiente dos estagiários na psicanálise. 0 que constatamos é que não há um percurso que torne possível a sustentação de um trabalho clínico pelos alunos. Não temos dispositivos que garantam a análise desses alunos como via principal para o trabalho nos núcleos de estágio, 
contamos com o compromisso desses estagiários ao rigor ético da psicanálise, o que, até o momento tem sido possível. Há de se considerar, ainda, que o saber em causa na psicanálise, está na contramão do que é visado na academia. Como mostramos, para a psicanálise, estamos submetidos a esse saber, o inconsciente nos sabe. Assim, nos encontramos afetados por um saber advindo de outro lugar, e, que só se faz avançar ao preço de muita angústia, pois aponta para a falta constitutiva.

Assim, endossamos com esse trabalho, que a tarefa de refletir sobre as possibilidades de uma prática em meio à estrutura acadêmica, não é fácil. Podemos, inclusive, afirmar que as tentativas de ensinar psicanálise fora do tripé analítico - ensino, análise pessoal e supervisão clínica - provocariam a impossibilidade de transmiti-la. Quando falamos de transmissão fazemos referência ao saber inconsciente, por isso não se trata, unicamente, do ensino e muito menos de sua burocratização.

No entanto, mesmo considerando todos os limites da relação universidade e psicanálise, sobretudo, no que consiste a sua prática em uma clínica-escola, entendemos, nesse momento, com o trabalho que ora apresentamos, poder abrir um espaço para que o aluno tenha alguma vivência no âmbito da experiência de escuta do sujeito, em que o sintoma é algo que fala, e que, por isso, a posição do sujeito, em relação a ele, deve ser retificada. É com uma ética, bem definida, que podemos advertir os alunos de que, nesse caso, não se trata de uma experiência de treino ou desenvolvimento de uma técnica, mas sim de um fato da clínica - o sujeito desejante.

Nesse sentido, acreditamos que mais que abordar os desencontros dos fundamentos que sustentam a psicanálise com a estrutura acadêmica, podemos pensar nas relações que se estabelecem nos atendimentos clínicos e nas supervisões como uma possibilidade de abrir caminhos para que o aluno possa ir além, melhor dizendo, lançar-se em busca de uma formação analítica. O que deve estar claro é que a academia não é apoio para o ensino da psicanálise, não é lugar de acesso à sua prática, tampouco, pode ser tomada como lugar de formação de analista.

Isso não nos impede de considerar que a universidade pode ter uma função importante de impulsionar e abrir caminhos para o ensino teórico. No nível da graduação não se desconsidera o ensino de noções gerais e conceituais de psicanálise. Por outro lado, a prática clínica é interrogada por só ser transmissível por via transferencial, o que implica um saber que vem de outro lugar, um saber inconsciente, fruto da experiência de cada um, e, portanto, consequência de um percurso de análise.

Enfim, acredita-se que a psicanálise tem encontrado um espaço propício para sua difusão no ambiente acadêmico, no entanto, precisa ser recorrentemente questionada em virtude da singularidade do seu campo e das 
limitações a que está submetida quando inserida na universidade. Este é o desafio que o cotidiano do nosso trabalho nos tem convocado.

\section{DECLARAÇÃO DE CONFLITOS DE INTERESSE}

Os autores declaram não haver conflitos de interesse.

\section{REFERÊNCIAS}

Araújo, M. A. P. (2005). A psicologia no Maranhão: Percursos históricos. São Luís, MA: EDUFMA.

Féres-Carneiro, T. (2013). Departamento de psicologia da PUC-Rio: 60 anos de formação e produção de conhecimento. Psicologia Clínica, 25(2), 233-241. doi: $10.1590 /$ S0103-56652013000200014

Figueiredo, A.C., \& Vieira, M. A. (2002). Psicanálise e ciência: Uma questão de método. In W. Beividas (Org.), Psicanálise, pesquisa e universidade (p.1331). Rio de Janeiro, RJ: Contra Capa.

Freud, S. (1996). A dinâmica da transferência. In Edição standard brasileira das obras psicológicas completas de Sigmund Freud (vol. 12). São Paulo, SP: Imago. (Original publicado em 1912).

Freud, S. (1996). A questão da análise leiga. In Edição standard brasileira das obras psicológicas completas de Sigmund Freud (vol. 20), São Paulo, SP: Imago. (Original publicado em 1926).

Freud, S. (1996). O sentido do sintoma. In Edição standard brasileira das obras psicológicas completas de Sigmund Freud (vol. 16). São Paulo, SP: Imago. (Original publicado em 1916).

Freud, S. (1996). Sobre o ensino da psicanálise na universidade. In Edição standard brasileira das obras psicológicas completas de Sigmund Freud (vol. 17). São Paulo, SP: Imago. (Original publicado em 1919).

Freud, S. (1996). Um caso de histeria. In Edição standard brasileira das obras psicológicas completas de Sigmund Freud (vol. 7). São Paulo, SP: Imago. (Original publicado em 1905).

Góes, M. I. (2009). A regulamentação, a psicanálise e as psicoterapias. In S. Alberti (Org.), O ofício do psicanalista: Formação versus regulamentação (pp. 89-98). São Paulo, SP: Casa do Psicólogo.

Lacan, J. (1998). A direção do tratamento e os princípios do seu poder. In Escritos. Rio de Janeiro, RJ: Jorge Zahar Ed. (Trabalho original publicado em 1958).

Lacan, J. (1998). O seminário: Os quatro conceitos fundamentais da psicanálise. (Livro 11). Rio de Janeiro, RJ: Jorge Zahar Ed. (Original publicado em 1964). 
Lacan, J. (1994). Variantes de um tratamento Padrão. In Escritos. Rio de Janeiro, RJ: Jorge Zahar Ed. (Original publicado em 1955).

Ministério da Educação. (2000). Padrões de qualidade para cursos de graduação em psicologia. Brasília, DF: MEC. Recuperado de http://portal.mec.gov.br/sesu/arquivos/pdf/psicologia.pdf

Ministério do Trabalho e do Emprego. (2002). CBO - Classificação Brasileira de Ocupação. Portaria no 397, de 09/10/2002. Recuperado de http://www.mtecbo.gov.br/

Oliveira. C. L. M. V. (2014). Psicanálise e universidade: A trajetória paulista. In Anais do Sexto Congresso Internacional de Psicopatologia Fundamental. Belo Horizonte, MG: PUC-MG. Recuperado de http://www.fundamentalpsychopathology.org/uploads/files/Anais\%20Congr esso\%202014/Mesas\%20Redondas/17.1.pdf

Presidência da República do Brasil. (1962). Lei 4.119 de 27 de agosto de 1962. Recuperado de http://www.planalto.gov.br/ccivil_03/leis/1950969/L4119.htm

Presidência da República do Brasil. (2008). Lei no 11.788, de 25 de setembro de 2008. Recuperado de http://www.planalto.gov.br/ccivil_03/_ato20072010/2008/lei/l11788.htm

\section{Sobre os autores}

Wânia Suely Santos da Silva é psicóloga pela Universidade da Amazônia, mestre em Psicologia Social pela Universidade do Estado do Rio de Janeiro.

waniasilva2013@uol.com.br

Luhilda Ribeiro Silveira é psicóloga pela Universidade Federal do Maranhão, mestranda em Gestão da Informação pela Universidade do Estado de Santa Catarina. luhilda@yahoo.com.br

Gleiciane Mendes Costa da Silva é psicóloga pela Universidade Federal do Maranhão. gleiciane.m.costa@gmail.com

Luiza Adelaide Vieira Naue é estudante de psicologia da Universidade Federal do Maranhão. lu.izaa@hotmail.com

Wânia Suely Santos da Silva; Luhilda Ribeiro Silveira; Gleiciane Mendes Costa; e Luiza Adelaide Vieira Naue - contribuíram para a investigação do artigo, bem como participaram da redação inicial do artigo (rascunho); Wânia Suely Santos da Silva - contribuiu com o suporte da fundamentação teórica e de seus ajustes e correções; Luhilda Ribeiro Silveira - responsável pela normalização do artigo; Wânia Suely Santos Silva e Luhilda Ribeiro Silveira - responsáveis pela redação final (revisão e edição).

Recebido em: 19/07/2016

Revisado em: 21/12/2016

Aceito em: $12 / 02 / 2017$ 